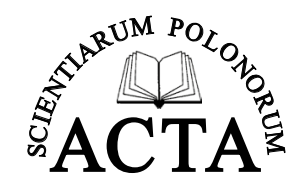

www.food.actapol.net

Acta Sci. Pol. Technol. Aliment. 16(1) 2017, 83-91

pISSN 1644-0730

eISSN 1889-9594

http://dx.doi.org/10.17306/J.AFS.2017.0442

REVIEW PAPER

Received: 19.09.2016

Accepted: 29.12.2016

\title{
THE GENETIC BASIS OF OBESITY COMPLICATIONS
}

\author{
Katarzyna Skrypnik ${ }^{1 凶}$, Joanna Suliburskaํ, Damian Skrypnik², Łukasz Pilarski², \\ Julita Reguła1, Paweł Bogdański
}

${ }^{1}$ Department of Human Nutrition and Hygiene, Poznań University of Life Sciences

Wojska Polskiego 31, 60-624 Poznań, Poland

2Department of Internal Medicine, Metabolic Disorders and Hypertension, Poznań University of Medical Sciences Szamarzewskiego 84, 60-569 Poznań, Poland

${ }^{3}$ Department of Education and Obesity Treatment and Metabolic Disorders, Poznań University of Medical Sciences

Szamarzewskiego 84, 60-569 Poznań, Poland

\begin{abstract}
Intensive research is currently being performed into the genetic background of excess body mass complications such as diabetes, cardiovascular disorders, especially atherosclerosis and coronary heart disease. Chronic inflammation is an important process in the pathogenesis of obesity, wherein there is an aberrant expression of genes encoding adipokines. Visceral tissue is characterized by a higher expression and secretion of interleukin-8, interleukin- $1 \beta$ and plasminogen activator inhibitor 1 in the subcutaneous tissue secretion of leptin prevails. An important complication of obesity is obstructive sleep apnea, often observed in PraderWilli syndrome. The genetic background of sleep apnea may be a polymorphism of the SREBF1 gene. The consequence of excess body mass is metabolic syndrome, which may be related to the occurrence of the rs926198 variant of gene encoding caveolin-1. The genes of transcription factor TCF7L2 and PPAR- $\gamma 2$ take part in the pathogenesis of diabetes development. It has been demonstrated that oncogenes FOS, FOSB, and JUN may be co-responsible not only for obesity but also for osteoporosis and colorectal cancer. It has been shown that weight loss causes a modification in the expression of about 100 genes involvedt in the production of substances such as cytokines and other responsible for chronic inflammation in obesity. In future studies on the complications of obesity, such scientific disciplines as proteomics, peptidomics, metabolomics and transcriptomics should be used. The aim of this study is to present the current state of knowledge about the genetic basis of obesity complications.
\end{abstract}

Keywords: obesity, obesity complications, genetic background

\section{INTRODUCTION}

Obesity is associated with systemic chronic inflammation (Frohlich et al., 2000). This condition is a risk factor of metabolic diseases and cardiovascular diseases significantly increasing mortality in patients with excessive weight (Fest et al., 2000). The most important inflammatory markers include CRP (C-reactive protein), IL-6 (interleukin-6) and TNF- $\alpha$ (tumor necrosis factor alpha). An increased concentration of these substances in the blood is associated with the occurrence of conditions such as insulin resistance, coronary heart disease and type 2 diabetes mellitus (Vozarova et al., 2001). Adipose tissue, an important endocrine organ, secretes many biologically active substances, such as adipokines (including leptin and adiponectin) and chemokines. They play a key role in the pathogenesis of atherosclerosis. Understanding the molecular

凶katarzyna.skrypnik@gmail.com 
mechanisms through which they function in the human body is crucial for the creation of new therapeutic strategies for obesity and its complications. It appears that each stage of obesity development - weight gain, its maintenance and response to diet and physical activity is associated with unique genetic mechanisms (Mercer et al., 2004). Therefore, the genetic aspects of obesity complications is currently one of the most extensively explored areas of modern medicine. Research on the genetics of inflammation associated with fatty tissue has recently been highly improved thanks to two molecular techniques: RT-qPCR (reverse transcription-quantitive polymerase chain reaction) and DNA chips (DNA microarray). The first technique has increased the efficiency and reproducibility of reverse transcription of mRNA to cDNA, even with small amounts of tissue samples. This is particularly important in the case of adipose tissue, which has a very low efficiency in the process of obtaining RNA, due to the presence of more than $90 \%$ of dry weight of lipids. DNA chips will allow to perform a quantitative identification of thousands of genes in one experiment, which makes it a standard tool in the study of obesity (Copland et al., 2003; Wong and Medrano, 2005).

The aim of this study is to present the current state of knowledge about the genetic basis of obesity complications.

\section{OBESITY AND THE EXPRESSION OF FACTORS REGULATING INFLAMMATION}

Subcutaneous and visceral adipose tissue differ in terms of the gene expression of inflammatory factors and adipokines. Visceral tissue is characterized by a higher expression and secretion of interleukin- 8 (IL-8), interleukin-1ß (IL-1ß) and plasminogen activator inhibitor 1 (PAI-1). Secretion of leptin prevails in subcutaneous tissue. Interleukin-6 (IL-6) is secreted by both types of adipose tissue in both obese and normalweight people (Clement and Langin, 2007). Expressions of genes involved in the immune response also depend on the type of adipose tissue - immunoglobulins and complement proteins are intensively produced in visceral adipose tissue, as well as carboxypeptidaseE, thrombospondin 1 and visfatin. Previous studies allow researchers to conclude that the main source of proinflammatory and prothrombotic factors associated with visceral adipose tissue are macrophages (Clement and Langin, 2007).

\section{ADIPONECTIN - THE ADIPOKINE OF SPECIAL ROLE}

The adiponectin gene polymorphism is given as the cause of changes in the amount of adiponectin mRNA in adipose tissue of some obese subjects on a lowcalorie diet (Clement and Langin, 2007). Lanas et al. (2015) performed a study on a population of 108 adult patients, divided into four groups of 27 people depending on sex and obesity. The relationship of adiponectin and both clinical and genetic factors was studied. Besides anthropometric parameters, the serum concentration of adiponectin, glucose, insulin, CRP and selected variants of polymorphisms of gene encoding adiponectin (rs1501299, rs2241766, rs266729 and rs17300539) were assessed, as well as the physical activity level, risk factors for cardiovascular disease and the treatment implemented. The inverse relationship of adiponectin to abdominal circumference, waist-tohip ratio (WHR - waist-hip ratio), body weight, body mass index (BMI - body mass index), serum insulin and HOMA-IR (homeostatic model assessment) and physical activity was revealed. It was also found that the average concentration of adiponectin was lower in men $(p=0.015)$, obese patients $(p<0.01)$, patients with low physical activity $(p=0.015)$ and with a diagnosis of insulin resistance $(p=0.005)$. The GG genetic variant (rs 1501299) was associated with a lower adiponectin concentration than TT and GT variants $(p$ $=0.006$ ). In other gene variants, adiponectin concentrations were similar. The study confirmed the relationship of adiponectin with gender, obesity, physical activity and insulin resistance, but the influence of selected genetic factors was poorly marked.

Kieć-Klimczak et al. (2008) evaluated the leptinto-adiponectin ratio (Lep/AdipoR) in the blood of patients from obese families. The study was conducted on 80 subjects (43 women and 37 men). Patients underwent anthropometric measurements, body fat content measurement, oral glucose tolerance test (OGTT) and oral postprandial lipemia test (OPLD). Fasting leptin, adiponectin and von Willebrand factor serum concentration were measured. During the OGTT, blood samples were taken at 30-minute intervals up 
to two hours to determine the concentration of glucose and insulin. The level of serum adiponectin was higher in women than in men and iminished with the decrease in BMI, regardless of gender. The serum concentration of leptin positively correlated with BMI. Patients with low serum levels of adiponectin (below $5 \mathrm{mg} / \mathrm{ml}$ in males and $10 \mathrm{mg} / \mathrm{ml}$ in females) had the highest serum concentration of glucose and insulin in OGTT time points and the highest HOMA-IR (4.79 in men and 4.38 in women). Patients with high levels of serum leptin had the highest concentration of insulin, particularly in the 2nd hour of OGTT, and the highest HOMA-IR. The leptin-to-adiponectin ratio was significantly higher in obese patients compared to those with normal BMI. This ratio also correlated with BMI, HOMA-IR, and with the concentration of fasting insulin. ROC analysis (receiver operating characteristic or relative) showed that leptin-to-adiponectin ratio had the highest discriminative value for the obesity. Therefore, this ratio can be used to assess the severity of obesity complications, such as insulin resistance and endothelial dysfunction.

Adiponectin is responsible for regulating the expression of miR-335, microRNA performing an important role in the complications of obesity. Studies have shown that miR-335 expression significantly increases with an increase in the concentrations of leptin, resistin, TNF- $\alpha$, IL-6 in the mature human adipocytes and with maturation of adipocytes. Regulation of the transcription of miR-335 by these adipokines is independent of the native gene (the gene MEST). Accordingly, the occurrence of complications of obesity caused by the function of miR-335 is dependent on his own mechanisms of transcription regulated by the presence of the adipokines (Zhu et al., 2014).

\section{THE INCREASE OF CARDIOVASCULAR RISK IN OBESITY - THE SEARCH FOR GENETIC RELATIONS}

Bielicki, et al. (2014) investigated the relationship between polymorphisms of selected genes possibly associated with coronary heart disease with a prevalence of obstructive sleep apnea (OSA). Their study involved 600 people with OSA, including 127 people with coronary heart disease and the other 473 as the control group. Polymorphism of three genes: SREBF1,
REBF2 and HIF 1 was investigated for ischemic heart disease or myocardial infarction. These gene polymorphisms did not disclose a relationship with the occurrence of coronary heart disease in patients with OSA. Analysis of the relationship between polymorphisms of selected genes and coronary heart disease in all patients with OSA revealed a relationship only for the SREBF1 gene. The lowest prevalence was observed for AA homozygotes (13.6\%) and GG homozygotes $(26.1 \%)$.

OSA is often observed in Prader-Willi syndrome (PWS) caused by a deletion of the long arm of chromosome 15. Obesity is one of the main symptoms of PWS. This disease, in addition to excess body weight, is characterized by low growth and muscle hypotonia. Matsuura et al. (2008) described a case of a 23-year-old woman with PWS, complicated by obese hypoventilation syndrome. The disease was diagnosed in 1 year and the patient was treated with a growth hormone, and due to the narrow pharynx - the operation of larynx and pharynx was performed. When the patient's body weight increased to $96 \mathrm{~kg}(\mathrm{BMI}=$ $51 \mathrm{~kg} / \mathrm{m}^{2}$ ), the woman began to suffer from drowsiness, cyanosis, snoring and night awakening. The patient was admitted to hospital due to loss of consciousness. On admission severe hypoxia and significant hypercapnia were diagnosed. A chest X-ray showed cardiomegaly with massive effusion. After a week of hospitalization, polysomnography showed the value of AHI (apnea/hypopnea index) 16, which indicates moderate severity of OSA with an average of nocturnal oxygen saturation (oxygenation of peripheral blood) at $74 \%$, which indicates significant hypoxia. Accordingly, the non-invasive positive pressure ventilation (NPPV) was implemented, which resulted in a significant improvement in her health. The patient was discharged from hospital in a state of improvement, with the recommendation of NPPV continuation.

Baudrand et al. (2015) conducted a study on the association of the rs 926198 variant of the gene encoding caveolin-1 (CAV1) with the development of metabolic syndrome, a factor significantly increasing the cardiovascular risk, in two populations - 735 people of Caucasian and 810 of Hispanic origin. In the Caucasian population the allele being studied was associated with a significantly increased cardiovascular risk assessed by the Framingham Risk Score $(p=0.016)$, 
higher risk of metabolic syndrome $(p<0.001)$, diabetes $(p=0.016)$, insulin resistance $(p=0.022)$ and lower serum HDL level $(p=0.018)$. An association with the development of metabolic syndrome was also shown for the population of Hispanic origin $(\mathrm{OR}=$ $2.83, p=0.025)$. Thin individuals who carried a variant of the investigated allele demonstrated a significantly higher risk of metabolic syndrome $(\mathrm{OR}=3.87$, $p<0.001)$ and diabetes mellitus $(\mathrm{OR}=2.27, p=0.03)$ development. There was no evidence, however, of such a relationship for obese people. The authors found that the risk of metabolic syndrome is modified by the interaction between the CAV1 gene variant and the status of BMI. A family history of metabolic syndrome in investigated allele carriers was shown.

There is a strong relationship between the gene of transcription factor TCF7L2 and PPAR- $\gamma 2$ receptors and the occurrence of type 2 diabetes mellitus in many populations. Al-Safar et al.'s (2014) study of 272 patients suffering from type 2 diabetes and 216 healthy people showed the impact of the presence of the rs10885409 C allele of TCF7L2 gene and the lack of abovementioned impact in case of a Pro12Ala (rs 1801282) mutation of the PPAR- $\gamma 2$ gene on the risk of diabetes in an Arab population. In addition, a modulating effect of obesity on this risk regarding the rs 10885409 C allele of TCF7L2 gene was found. In diabetes and obesity the presence of many modifications within the mitochondria, which may be the result of abnormal blood glucose and blood lipid concentration and abnormal insulin signaling pathway, were observed. Zheng et al. (2015) have shown that insulin resistance in diabetes and obesity may be an effect of a reduced amount of mtDNAn and of abnormal genetic and epigenetic regulation of insulin function within the mitochondria.

Recent studies have shown a link between SLC16A11 gene variants with the development of type 2 diabetes in the inhabitants of Mexico and other Latin American countries. A haplotype of this gene, designated as allele rs75493593 A, responsible for the higher risk of diabetes development occurs in $50 \%$ of Indians living in the area of Mexico, but is rare in populations of Europe and Africa. Traurig et al. (2016) performed a study on the SLC16A11 gene in a population of 12,811 indigenous people of North America. The study showed a theoretical connection between the allele being investigated and type 2 diabetes $(p=0.001, \mathrm{OR}=1.11)$, but a strong influence of high BMI on the findings $\left(p=5.1 \times 10^{-7}\right)$ was observed. The influence of this allele on the development of type 2 diabetes was greater in leaner individuals. In people with type 2 diabetes, a very strong relationship between rs75493593 A allele and BMI $\left(p=3.4 \times 10^{-15}\right)$ was demonstrated, not observed in patients without diabetes $(p=0.77)$. The authors suggest that it may be related to greater weight loss in people who carry this allele and suffer from type 2 diabetes $(p=0.02)$. Furthermore, an analysis of gene expression data indicated the connection of investigated allele with the expression of the RNASEK gene, indicating the possible mediating effects of this gene in the development of type 2 diabetes.

Improperly treated diabetes leads to ophthalmic complications - diabetic retinopathy (DR). There is evidence that the development of diabetic retinopathy is affected by genetic factors. The purpose of a study by Cyganek et al. (2006) was to define the incidence of diabetic retinopathy in a group of 267 Polish patients with type 2 diabetes, to determine the clinical features associated with DR and to search for a connection between vitamin D receptor (VDR) gene - a candidate gene for vascular complications of diabetes - and with DR. The experimental group consisted of 146 women and 121 men with type 2 diabetes. Clinical and metabolic profile of the subjects was described. Based on the Restriction Fragment Length Polymorphism method, patients were genotyped for the presence of four VDR gene polymorphisms. DR was detected in $31.8 \%$ of patients. Multivariate analysis revealed that significant factors predicting this complication were: the status of never-smoker, the level of urea in the serum, the concentration of serum glycated hemoglobin and insulin treatment. Other factors such as the age at which type 2 diabetes was diagnosed, the time that has passed since the last ophthalmic examination, obesity, serum creatinine concentration, the albumin/creatinine ratio and hypertension were single-risk factors of DR, but in multivariate analysis they showed poor validity. Similarly, alleles, genotypes, haplotypes and combinations of haplotypes of VDR were not connected with DR development. In conclusion, the study showed that DR in patients with type 2 diabetes is a common complication among the Polish population. It was 
demonstrated that VDR gene polymorphism is not a risk factor of DR.

Genetics links obesity with atherogenesis. It has been shown that weight loss results in a decrease in the expression of the gene encoding the amyloid A (SAA - serum amyloid A) present in blood serum. This polyprotein produced in the liver is involved in the transport of cholesterol. Expression of the SAA gene correlates with the size of the adipocytes and is increased in obese people (Clement and Langin, 2007). Another important biomarker of cardiovascular complications of obesity is cysteine protease cathepsin S. Its level is significantly increased in atherosclerotic plaques with a total lack of its gene expression in normal arteries. Cathepsin $\mathrm{S}$ is produced and released locally by preadipocytes and is involved in the increase in body fat mass, which helps to explain the occurrence of severe atherosclerosis in obese subjects (Clement and Langin, 2007).

\section{ONCOGENESIS IN OBESITY}

Epidemiological studies have shown a link between obesity and colon cancer. Many researchers concluded that colon cancer can be considered as a complication of excess body weight. To identify the genetic basis of this phenomenon, Chen et al. (2015) created a digital analytical tool, which allowed a multimillion population to be analysed. They identified metabolic syndrome, diabetes and insulin resistance as a link between obesity and colorectal cancer. In addition, it was found that osteoporosis is a disease associated significantly with coexisting colon cancer and obesity. In all three states, the expression of six genes: PPP1R15A, HADHA, NRIP1, FOS, FOSB, and JUN is observed. The last three of these are oncogenes. In contrast, the genes PPP1R15A, HADHA and NRIP1, despite their involvement in the pathogenesis of metabolic syndrome and diabetes, do not participate in the development of insulin resistance.

Researchers postulate the existence of genetic factors in the pathogenesis of nonalcoholic fatty liver disease (NAFLD) - a serious complication of obesity. NAFLD involves a series of pathological disorders of the liver, including steatosis, the non-alcoholic steatohepatitis (NASH-) and cirrhosis. The advanced form of NAFLD can lead to liver cancer. The pathogenesis of NAFLD includes excessive supply of food and lack of physical activity, insulin resistance and genetic factors. The prevalence of NAFLD is estimated at $17-33 \%$, NASH is present in $1 / 3$ cases of NAFLD, whereas $20-25 \%$ of NASH can progress to cirrhosis. NAFLD is now recognized as one of the most common causes of elevated liver enzyme serum concentration without clinical symptoms. Early stages of NAFLD are clinically asymptomatic and can present as elevated serum concentrations of alanine transaminase (ALT) and gamma-glutamyl transferase (GGT), increased echogenicity of the liver in ultrasound and as an enlarged liver in a physical examination. Abdominal discomfort and chronic fatigue are the most common clinical symptoms of NAFLD. NAFLD/NASH is a relatively dangerous disease; liver biopsies show the progression of fibrosis in $32 \%$ of patients, and the estimated growth rate of cirrhosis is $20 \%$. $12 \%$ of patients die within 10 years of diagnosis (Raszeja-Wyszomirska et al., 2008). The most important method of treatment is to increase insulin sensitivity by lifestyle changes, primarily by the implementation of a proper diet and physical activity to reduce body weight (Raszeja-Wyszomirska et al., 2008; Skrypnik et al., 2016). The most commonly used drug in the treatment of NAFLD is metformin, other medications are still at the research stage and their effectiveness is low (Raszeja-Wyszomirska et al., 2008).

\section{GENETIC FACTORS AND TREATMENT OF OBESITY}

It has been shown that weight loss achieved as a result of a very low calorie diet (VLCD) causes a modification in the expression of about 100 genes within the subcutaneous adipose tissue responsible for the production of substances such as cytokines, interleukins, complement components, acute phase proteins and molecules responsible for the communication between cells and extracellular matrix remodeling. The decrease in the expression (down regulation) of genes responsible for synthesis of the inflammatory factors is especially marked. This phenomenon explains the reduction or even resolution of chronic inflammation seen in obese people who have returned to normal body weight (Clement et al., 2002). These observations were confirmed in a large-scale study on patients who underwent bariatric surgery. This improvement in 
the profile of inflammation is accompanied by a reduction in the adipose tissue infiltration by macrophages and by a change in these macrophages' phenotype, resulting in the increased expression of anti-inflammatory agents such as interleukin-10 (IL-10) and interleukin-1 receptor antagonist (IL1-Ra) (Cancello et al., 2005). The stimulus causing tissue infiltration by macrophages is local tissue hypoxia. Expression of hypoxia-inducible factor $1 \alpha(\mathrm{HIF}-1 \alpha)$ is significantly increased in obese patients, and it decreases with a reduction in body weight (Guerre-Millo et al., 2002).

Marín et al. (2015) studied the effect of dietary intake of seeds and oil of Salvia hispanica L. on the health of rats with diet-induced obesity. They showed that the addition of seeds and oil of Salvia hispanica $\mathrm{L}$. to a diet high in fat and fructose significantly improves glucose tolerance. The supply of these seeds and oil, both in 6 and 12-week treatment, increased the expression of the HSP25 and HSP70 gene of heat shock protein (HSP) in skeletal muscle, while a 6-week supply of these seeds increased expression of HSP70 gene only. The supply of oil from Salvia hispanica L. improved the expression of the superoxide dismutase gene and glutathione peroxidase gene. Furthermore, 12-week treatment with seeds and 6-week treatment with Salvia hispanica L. oil increased PGC-1 $\alpha$ (peroxisome proliferator-activated receptor-gamma coactivator) gene expression. It is therefore possible to conclude that treatment with oil of Salvia hispanica L. is more effective compared to seeds in the treatment of obesity's metabolic complications.

The impact of exercise on the profile of proinflammatory genes in adipose tissue is poorly understood. In two independent studies, one a three-month study of obese women performing endurance training, and the second on obese men undergoing 3-month strength training, no changes in adiponectin, IL- 6 and TNF- $\alpha$ gene expression were observed, despite the decrease in weight and insulin resistance (Klimcakova et al., 2006; Polak et al., 2006).

\section{GENETICS IN BARIATRIC SURGERY}

Chen et al. (2007) found that the polymorphism Ala$55 \mathrm{Val}$ of the UCP 2 gene plays a key role in the development of obesity and weight loss in patients undergoing laparoscopic adjustable gastric banding (LAGB).
Their study involved 304 obese patients (BMI $\geq 39$ $\mathrm{kg} / \mathrm{m}^{2}$ ); in 77 patients LAGB was performed, remaining patients underwent a laparoscopic mini-gastric bypass (LMGB). The control group consisted of 304 patients with normal weight. All patients underwent genotyping for the presence of four single nucleotide polymorphisms (SNPs) of the UCP 2 gene. SNPs significantly associated with obesity have been identified as affecting weight loss. Afterwards, the impact of candidate SNPs on weight loss in patients undergoing LAGB and LMGB respectively was examined. It was shown that the Ala55Val polymorphism of exon 4 of the UCP 2 gene is associated with obesity. Obese patients who have undergone LAGB with genotype TT or CT in rs660339 location experienced greater weight loss compared to those with the CC genotype after 12 and 24 months. This phenomenon was not observed in patients undergoing LMGB. Although greater weight loss is observed in patients who have LMGB, this procedure has a higher rate of complications than LAGB. Accordingly, the Ala55Val polymorphism can play an important role in the development of obesity and weight loss after LAGB. Ala55Val polymorphism of the UCP 2 gene can be used as a prognostic marker of expected weight loss after bariatric surgery.

\section{GENETICS OF OBESITY COMPLICATIONS - PERSPECTIVE}

In recent research, special attention has been paid to the fact that two compartments of subcutaneous adipose tissue can be separated: superficial subcutaneous adipose tissue (SSAT) located between the skin and the subcutaneous fascia and deep subcutaneous adipose tissue (DSAT) located below the fascia. It has been shown that SSAT is characterized by a high expression of the adiponectin gene and several other genes involved in metabolism, whereas in DSAT an overexpression of proinflammatory factor genes is observed. Furthermore, SSAT is characterized by hypertrophy of the adipocytes with lower infiltration by inflammatory factors and a smaller diameter of the lumen of blood vessels compared to DSAT. Regarding these differences in morphology and function, SSAT and DSAT should be considered independent elements affecting the obesity complications development (Cancello et al., 2013). 
Table 1. The most important genes involved in the development of obesity complications

\begin{tabular}{|c|c|c|}
\hline Gene/mutation & $\begin{array}{l}\text { Function in the development of obesity } \\
\text { complications }\end{array}$ & Author \\
\hline $\begin{array}{l}\text { Gene of adiponectin (variants rs } 1501299, \\
\text { rs } 2241766, \text { rs } 266729 \text { and rs17300539) }\end{array}$ & marker of cardiometabolic risk & Lanas et al. (2015) \\
\hline SREBF1 & $\begin{array}{l}\text { responsible for increased risk of coronary heart } \\
\text { disease in patients with obstructive sleep apnea }\end{array}$ & Bielicki et al. (2014) \\
\hline Deletion of the long arm of chromosome 15 & $\begin{array}{l}\text { Prader-Willi syndrome - increased obstructive } \\
\text { sleep apnea risk }\end{array}$ & Matsuura et al. (2008) \\
\hline $\begin{array}{l}\text { rs926198 variant of the gene encoding } \\
\text { caveolin-1 }\end{array}$ & increased cardiovascular risk in obesity & Baudrand et al. (2015) \\
\hline $\begin{array}{l}\text { Genes of transcription factor TCF7L2 } \\
\text { and PPAR- } \gamma 2 \text { receptor }\end{array}$ & $\begin{array}{l}\text { occurrence of type } 2 \text { diabetes mellitus } \\
\text { in the obese }\end{array}$ & Al-Safar et al. (2015) \\
\hline SLC16A11 gene variants & $\begin{array}{l}\text { development of type } 2 \text { diabetes in the inhab- } \\
\text { itants of Mexico and other Latin American } \\
\text { countries }\end{array}$ & Traurig et al. (2016) \\
\hline Gene encoding the amyloid A & $\begin{array}{l}\text { the size of the adipocytes increased in obese } \\
\text { people }\end{array}$ & Clement and Langin (2007) \\
\hline $\begin{array}{l}\text { PPP1R15A, HADHA, NRIP1, FOS, FOSB, } \\
\text { and JUN }\end{array}$ & $\begin{array}{l}\text { coexistence of osteoporosis, colon cancer } \\
\text { and obesity }\end{array}$ & Chen et al. (2015) \\
\hline Polymorphism Ala55Val of UCP 2 gene & $\begin{array}{l}\text { weight loss in obese patients undergoing } \\
\text { laparoscopic adjustable gastric banding }\end{array}$ & Chen et al. (2007) \\
\hline
\end{tabular}

Many researchers emphasize the fact that in studies on the genetics of obesity and its complications many branches of molecular medicine, such as proteomics, peptidomics, metabolomics and transcriptomics, should be involved. Only by implementing the achievements of these disciplines and using their molecular tools can the pathogenesis of obesity be fully understood. Various types of digital programs such as MolPAGE (www.molpage.org), Diogenes (www. diogenes-eu.org) or HEPADIP (www.hepadip.org) allow multi-center researches on the molecular biology of obesity to be integrated. Through these programs significant gaps in contemporary obesitology, like the effects of the over-expression of inflammatory markers and adipokines on obesity complications, will be complemented (Clement and Langin, 2007).

\section{REFERENCES}

Al-Safar, H., Hassoun, A., Almazrouei, S., Kamal, W., Afandi, B., Rais, N. (2015). Association of the genetic polymorphisms in transcription factor 7-like 2 and peroxisome proliferator-activated receptors- $\gamma 2$ with type 2 diabetes mellitus and its interaction with obesity status in Emirati population. J. Diabet. Res., ID 129695. http:// dx.doi.org/10.1155/2015/129695

Baudrand, R., Goodarzi, M. O., Vaidya, A., Underwood, P. C., Williams, J. S., Jeunemaitre, X., ..., Pojoga, L. H. (2015). A prevalent caveolin-1 gene variant is associated with the metabolic syndrome in Caucasians and Hispanics. Metabolism, 64, 12, 1674-1681. http://dx.doi. org/10.1016/j.metabol.2015.09.005

Bielicki, P., Brzóska, K., Pływaczewski, R., Barnaś, M., Kumor, M., Stepkowski, T., ..., Śliwiński, P. (2014). Genetic predisposition to ischemic heart disease in patients with obstructive sleep apnea syndrome (OSAS). Pol. Merkur. Lek., 36, 214, 229-232.

Cancello, R., Henegar, C., Viguerie, N., Taleb, S., Poitou, C., Rouault, C., ..., Clément, K. (2005). Reduction of macrophage infiltration and chemoattractant gene expression changes in white adipose tissue of morbidly obese subjects after surgery induced weight loss. Diabetes, 54, 8, 2277-2286. 
Cancello, R., Zulian, A., Gentilini, D., Maestrini, S., Della Barba, A., Invitti, C., ..., Di Blasio, A. M. (2013). Molecular and morphologic characterization of superficial- and deep-subcutaneous adipose tissue subdivisions in human obesity. Obesity, 21, 12, 2562-2570. http:// dx.doi.org/10.1002/oby.20417

Chen, H. H., Lee, W. J., Wang, W., Huang, M. T., Lee, Y. C., Pan, W. H. (2007). Ala55Val polymorphism on UCP2 gene predicts greater weight loss In morbidly obese patients undergoing gastrin banding. Obes. Surg., 14, 7, 926-933.

Chen, Y., Li, L., Xu, R. (2015). Disease comorbidity network guides the detection of molecular evidence for the link between colorectal cancer and obesity. AMIA Jt Summits Transl. Sci. Proc., 2015, 201-206.

Clement, K., Viguerie, N., Diehn, M., Alizadeh, A., Barbe, P., Thalamas, C., ..., Langin, D. (2002). In vivo regulation of human skeletal muscle gene expression by thyroid hormone. Genom. Res., 12, 2, 281-291.

Clement, K., Langin, D. (2007). Regulation of inflammation-related genes in human adipose tissue. J. Intern. Med., 262, 4, 422-430.

Copland, J. A., Davies, P. J., Shipley, G. L., Wood, C. G., Luxon, B. A., Urban, R. J. (2003). The use of DNA microarrays to assess clinical samples: the transition from bedside to bench to bedside. Recent. Prog. Horm. Res., $58,25-53$

Cyganek, K., Mirkiewicz-Sieradzka, B., Malecki, M. T., Wolkow, P., Skupien, J., Bobrek, J., ..., Sieradzki, J. (2006). Clinical risk factors and the role of VDR gene polymorphisms in diabetic retinopathy in Polish type 2 diabetes patients. Acta. Diabetol., 43, 4, 114-119.

Festa, A., D’Agostino, R. Jr., Howard, G., Mykkänen, L., Tracy, R. P., Haffner, S. M. (2000). Chronic subclinical inflammation as part of the insulin resistance syndrome: the Insulin Resistance Atherosclerosis Study (IRAS). Circulation, 102, 1, 42-47.

Frohlich, M., Imhof, A., Berg, G., Hutchinson, W. L., Pepys, M. B., Boeing, H., ..., Koenig, W. (2000). Association between $\mathrm{C}$-reactive protein and features of the metabolic syndrome: a population-based study. Diabet. Care, 23, 12, 1835-1839.

Guerre-Millo, M., Grosfeld, A., Issad, T. (2002). Leptin is a hypoxiainducible gene. Obes. Res., 10, 8, 856.

Kieć-Klimczak, M., Malczewska-Malec, M., Huszno, B. (2008). Leptin to adiponectin ratio, as an index of insulin resistance and atherosclerosis development. Przegl. Lek., 65, 12, 844-849.

Klimcakova, E., Polak, J., Moro, C., Hejnova, J., Majercik, M., Viguerie, N., ..., Stich, V. (2006). Dynamic strength training improves insulin sensitivity without altering plasma levels and gene expression of adipokines in subcutaneous adipose tissue in obese men. J. Clin. Endocrinol. Metab., 91, 12, 5107-5112. https://dx.doi. org/10.1210/jc.2006-0382

Lanas, F., Serón, P., Saavedra, N., Ruedlinger, J., Salazaret, L. (2015). Genetic and non-genetic determinants of circulating levels of adiponectin in a cohort of Chilean subjects. Mol. Diagn. Ther., 19, 4, 197-204. http://dx.doi. org/10.1007/s40291-015-0146-3

Marineli, R. S., Moura, C. S., Moraes, É. A., Lenquiste, S. A., Lollo, P. C., Morato, P. N., ..., Maróstica, M. R. Jr (2015). Chia (Salvia hispanica L.) enhances HSP, PGC$1 \alpha$ expressions and improves glucose tolerance in dietinduced obese rats. Nutrition, 31, 5, 740-748. http:// dx.doi.org/10.1016/j.nut.2014.11.009

Matsuura, Y., Ameku, K., Numakura, T., Shiomi, T., Horie, T., Ohta, Y., Takasaki, Y. (2008). Prader-Willi syndrome associated with obesity hypoventilationsyndrome. Nihon Kokyuki Gakkai Zasshi., 46, 9, 748-752.

Mercer, J. G., O’Reilly, L. M., Morgan, P. J. (2004). Increasing the impact of European obesity research in preparation for the European research area: a report on the 2003 European Commission Obesity Workshop. Obes. Rev., $5,1,79-85$.

Polak, J., Klimcakova, E., Moro, C., Viguerie, N., Berlan, M., Hejnova, J., Richterova, B., ..., Stich, V. (2006). Effect of aerobic training on plasma levels and subcutaneous abdominal adipose tissue gene expression of adiponectin, leptin, interleukin 6 , and tumor necrosis factor alpha in obese women. Metabolism, 55, 10, 1375-1381. http://dx.doi.org/10.1016/j.metabol.2006.06.008

Raszeja-Wyszomirska, J., Lawniczak, M., Marlicz, W., Miezyńska-Kurtycz, J., Milkiewicz, P. (2008). Nonalcoholic fatty liver disease - new view. Pol. Merkur. Lekarski, 24, 144, 568-571.

Skrypnik, D., Ratajczak, M., Karolkiewicz, J., Mądry, E., Pupek-Musialik, D., Hansdorfer-Korzon, R., ..., Bogdański, P. (2016). Effects of endurance and endurance-strength exercise on biochemical parameters of liver function in women with abdominal obesity. Biomed. Pharm., 80, 1-7. http://dx.doi.org/10.1016/j. biopha.2016.02.017

Traurig, M., Hanson, R. L., Marinelarena, A., Kobes, S., Piaggi, P., Cole, S., ..., Bogardus, C. (2016). Analysis of SLC16A11 variants in 12,811 American Indians: Genotype-obesity interaction for type 2 diabetes and an association with RNASEK expression. Diabetes., 65, 2, 510-519. http://dx.doi.org/10.2337/db15-0571 
Vozarova, B., Weyer, C., Hanson, K., Tataranni, P. A., Bogardus, C., Pratley, R. E. (2001). Circulating interleukin-6 in relation to adiposity, insulin action, and insulin secretion. Obes. Res., 9, 7, 414-417. http://dx.doi. org/10.1038/oby.2001.54

Wong, M. L., Medrano, J. F. (2005). Real-time PCR for mRNA quantitation. Biotechniques, 39, 1, 75-85.

Zheng, L. D., Linarelli, L. E., Longhua, L., Wall, S. S., Greenawald, M. H., Seidel, R. W., ..., Cheng, Z. (2015). Insulin resistance is associated with epigenetic and genetic regulation of mitochondrial DNA in obese humans. Clin. Epigenetics., 7, 1, 60. http://dx.doi. org/10.1186/s13148-015-0093-1

Zhu, L., Chen, L., Shi, C. M., Xu, G. F., Xu, L. L., Zhu, L. L., ..., Ji, C. (2014). MiR-335, an adipogenesis-related microRNA, is involved in adipose tissue inflammation. Cell. Biochem. Biophys., 68, 2, 283-290. http:// dx.doi.org/10.1007/s12013-013-9708-3 http://dx.doi. org/10.1016/j.biopha.2016.02.017 
